\title{
CLIMATOLOGIA DA PROFUNDIDADE ÓTICA E DEPENDÊNCIA ESPECTRAL DE AEROSSÓIS EM REGIÕES DE FLORESTA E CERRADO NO BRASIL
}

\author{
MENEZES, Jorge Almeida de - jorgejamjam@gmail.com \\ Universidade Federal do Amazonas / UFAM \\ PALÁCIOS, Rafael da Silva - rafael.pgfa@gmail.com \\ Universidade Federal do Mato Grosso / UFMT
}

\begin{abstract}
MENEZES JÚNIOR, Evanizio Marinho de - evaniziomenezesjr2012@gmail.com
Universidade Federal do Amazonas / UFAM
\end{abstract}

NOGUEIRA, José de Souza - nogueira@ufmt.br

Universidade Federal do Mato Grosso / UFMT

\begin{abstract}
RESUMO: Aerossóis atmosféricos desempenham um papel importante no equilíbrio de energia do sistema Terra-atmosfera. Medidas de aerossóis foram realizadas em quatro sítios, dois em área de floresta (Rio Branco e Ji-Paraná) e dois em área de Cerrado (Cuiabá e Campo Grande), utilizando fotômetro solar da rede global AERONET. Dados de 5 anos permitiram classificar as propriedades ópticas dos aerossóis, definindo a climatologia para cada sítio. Neste trabalho a profundidade óptica de aerossol (AOD 440 $\mathrm{nm})$ e expoente Angstrom, $\alpha(440-870 \mathrm{~nm})$, foram utilizados para a análise espectral de aerossol. Médias de $\operatorname{AOD}(440 \mathrm{~nm})$ para sítios de Cerrado foram, respectivamente, 0,29 $( \pm 0,40), 0,18( \pm 0,24)$, com média correspondente de $\alpha 1,20( \pm 0,39), 1,16( \pm 0,36)$. Médias de AOD $(440 \mathrm{~nm})$ para sítios de Floresta são, respectivamente, 0,85( $\pm 0,71)$, $0,35( \pm 0,44)$, com média correspondente de $\alpha 1,38( \pm 0,41), 1,40( \pm 0,34)$. A AOD (440 $\mathrm{nm}$ ) tanto para regiões de Cerrado como de Floresta mostram picos distintos para estação seca e chuvosa, sendo que estão relacionados com padrões sazonais de aerossóis característicos dessas regiões. O $\alpha(440-870 \mathrm{~nm})$ apresentou modos de frequência que se relacionam com os principais tipos de aerossóis presentes tanto em Cerrado como em Floresta. Um cenário principal de aerossóis foi definido como aerossóis oriundos de queima de biomassa, com forte influência de fontes locais de aerossóis poluídos. Mistura de aerossóis estão presentes, enquanto que poeira em suspensão tem uma ocorrência pouco relevante.
\end{abstract}

PALAVRAS-CHAVE: AOD, expoente Angstrom, climatologia.

\section{CLIMATOLOGY STUDY OF OPTICAL PROPERTIES OF ATMOSPHERIC AEROSOLS IN FOREST AND CERRADO}

ABSTRACT: Atmospheric aerosols play an important role in the energy balance of the Earth-atmosphere system. Aerosol measurements were conducted at four sites, two in forest area (Rio Branco and Ji-Paraná) and two in Cerrado (Cuiabá and Campo Grande) using solar photometer AERONET global network. A database of 5 years has allowed the classification properties of these aerosols, defining the weather for each site. In this work aerosol optical depth AOD (440 nm) and Angstrom exponent, $\alpha(440-870 \mathrm{~nm})$, were used for aerosol analysis. The average AOD $(440 \mathrm{~nm})$ to the sites of Cerrado are, respectively, $0,29( \pm 0,40), 0,18( \pm 0,24)$, with a corresponding average of $\alpha 1,20( \pm 0,39)$ $1,16( \pm 0,36)$. Mean AOD $(440 \mathrm{~nm})$ for forest sites are, respectively, $0,85( \pm 0,71)$ $0,35( \pm 0,44)$, corresponding to an average of $\alpha 1,38( \pm 0,41) 1,40( \pm 0,34)$. The AOD both Cerrado regions as forest exhibit distinct peaks for dry and rainy season, and are related to seasonal patterns characteristic of aerosols in these regions. Exponent Angstrom has frequency modes which relate to the major types of aerosols present in both cerrado and forest. A main scenario of aerosols is defined as aerosols originating from biomass 
burning, with strong influence of local sources of contaminated aerosols. Aerosol mixture are present while airborne dust has little relevant occurrence.

KEYWORDS: AOD, Angstrom exponent, climatology.

\section{INTRODUÇÃO}

Aerossóis são minúsculas partículas que estão suspensas na atmosfera (OYEM, 2010). São compostos de misturas de sustâncias diferentes, tais como poeira, fumaça, matéria orgânica, gases poluentes e partículas em suspensão. Aerossóis são injetados na atmosfera a partir de fontes naturais e antropogênicas (TAN, 2015), tais como congelamento de vapor de água, condensação, queima de biomassa, erupção vulcânica, processos de remoção do solo através da agricultura e irrigação, incêndio florestal, vegetação, e sais inorgânicos secundários. São distribuídos na atmosfera por turbulência e circulação regional/global (ou seja, movimento de massas de ar). Os aerossóis são removidos a partir da atmosfera por precipitação, gelo, orvalho, e outras formas de precipitações. Podem também ser removidos através de sedimentação seca (influência da força da gravidade). As concentrações e distribuições de aerossóis na atmosfera são altamente variáveis no espaço e no tempo. Depende de fatores como localização, estações, condições atmosféricas, ciclos anuais e a presença de fontes locais (MUKHTAR BALARABE, 2016).

Devido a intensas alterações no uso do solo e ocupação humana na região amazônica tem-se observado emissões significativas de partículas de aerossóis para a atmosfera influenciado por queimadas, tanto de áreas de pastagem como de florestas primárias (ARTAXO, 2001). Além das emissões causadas por ação humana, a floresta amazônica, devido a sua localização tropical e intenso metabolismo, torna-se uma fonte importante de gases e vapor de água emitidos para a atmosfera regional e global. A intensa atividade convectiva presente na região, leva estes constituintes atmosféricos a grandes altitudes, onde podem ser transportados de modo eficaz a longa distância (ANDREAE, ARTAXO, et al., 2001).

Aumentos de partículas de aerossol na atmosfera podem afetar a transmissão da radiação solar através da dispersão e absorção (NWAFOR, 2007), que tem tanto consequências diretas e indiretas sobre o clima regional e global. Isto ocasiona diretamente também degradações de visibilidade (BALARABE, ABDULLAB e NAWAWI, 2015), que por sua vez podem afetar a economia da região. Além disso, a concentração de aerossol na atmosfera também pode afetar a qualidade do ar e da saúde humana (FLORENCE, YVON, et al., 2010). Os aerossóis provocam efeitos diretos, aumentando os núcleos de condensação de nuvens e, consequentemente, maior concentração de nuvem (OGUNJOKI, AJAYI, et al., 2008). A quantificação desses efeitos torna-se difícil devido aos tipos de particulado (resultado da sua variedade de fontes), o padrão e as interações existentes (HABID, VENKATARAMAN, et al., 2006). Para minimizar essa incerteza, muitos cientistas estão envolvidos no monitoramento constante da sua concentração e efeito em escala global e regional (PROSPERO, GINOUX, et al., 2002). Isto é possível através de medições de aerossóis e propriedades ópticas em escala global e regional. Algumas dessas medidas são realizadas em terra, avião ou satélites com diferentes escalas temporais. A AERONET (Aerosol Robotic Network) que é uma federação de redes de aerossóis de sensoriamento remoto estabelecidas pela NASA e pela PHOTONS, é considerada mais confiável para estudo de aerossóis locais e regionais em 
relação ao satélite. Muitos estudos sobre as propriedades ópticas de aerossóis (TAN, WEI, et al., 2015) são realizados utilizando a AERONET (HOLBEN, ECK, et al., 1998).

A dependência do comprimento de onda de $\operatorname{AOD}(440 \mathrm{~nm})$ (AOD - Aerosol Optical Delph) varia entre diferentes tipos de aerossóis por causa das suas diferentes características físicas e químicas. Esta dependência do comprimento de onda AOD (440 nm) é adequadamente expresso pelo Expoente Angstrom $(\alpha)$. A derivação de $\alpha$ em diferentes regiões de comprimento de onda é uma ferramenta útil para caracterizar e distinguir os diferentes tipos de aerossóis (ECK et al., 1999). O uso do expoente Angstrom, $\alpha$, aumentou significativamente durante os últimos anos, porque este parâmetro é facilmente estimado usando fotômetro solar de superfície automatizado, enquanto ele está se tornando cada vez mais acessível para consultas por satélite (SCHUSTER , DUBOVIK O e HOLBEN, 2006). Além de ser um instrumento útil para a extrapolação de AOD em toda a região espectral de onda curta, o valor do expoente Angstrom é também um indicador qualitativo de tamanho de partícula de aerossol ou fração moda fina (KAUFMAN, HOBBS, et al., 1998).

Os sítios de Ji-Paraná e Rio Branco, localizados em áreas de floresta, fornecem monitoramento contínuo de aerossóis atmosféricos. Os dados obtidos dão continuidade às medições no sítio de Ji-Paraná desde 10 de março de 2000 e no sítio de Rio Branco desde 04 de janeiro de 1994, com fotômetro solar. Os sítios de Campo Grande Sonda e Cuiabá MIRANDA, localizados em área de cerrado, também fornecem monitoramento de rotina, sendo os dados de medições obtidos para o sítio de Campo Grande Sonda desde 31 de outubro de 2003 e Cuiabá MIRANDA desde 06 de dezembro de 2000. Neste trabalho dois parâmetros fundamentais para a caracterização de aerossóis, profundidade óptica de aerossol AOD (440 nm) e Expoente Angstrom, $\alpha(440-870 \mathrm{~nm})$, foram utilizados para a análise espectral de aerossol.

Nesse sentido o objetivo desse trabalho foi realizar análise espectral da profundidade óptica de aerossóis AOD (440 nm) e expoente angstrom $\alpha$ (440$870 \mathrm{~nm}$ ) de sítios localizados em regiões de Floresta e Cerrado por serem parâmetros básicos para descrição de aerossol.

\section{MATERIAL E MÉTODOS}

\section{ÁREA DE ESTUDO}

Sensores terrestres instalados nos fotômetros solares da AERONET situados em locais de observação localizados nos sítios de floresta, Rio Branco $\left(9.95^{\circ} \mathrm{S}, 67.86^{\circ} \mathrm{W}\right)$, localizado no topo de uma torre de 22 metros e Ji-Paraná $\left(10.93^{\circ} \mathrm{S}, 61.85^{\circ} \mathrm{W}\right)$, situado em uma torre de água em um pasto, com algumas árvores dispersas com $100 \%$ de horizonte desobstruído, ambos localizados no estado de Rondônia e nos sítios de Cerrado, Cuiabá $\left(15.72^{\circ} \mathrm{S}, 56.02^{\circ} \mathrm{W}\right)$ instrumento localizado em uma plataforma em um campo e Campo Grande $\left(20.43^{\circ} \mathrm{S}, 54.53^{\circ} \mathrm{W}\right)$, situado em uma área rural perto dos limites da cidade são utilizados nessa pesquisa. Entre a área urbana e campus existem muitos parques de conservação da área urbana. 
A instrumentação é descrita em detalhes por Holben et al.,1998. Medidas de atenuação solar direta são realizadas a cada 15 minutos a 340, 380, 440, 500, 675, 870, 940 e $1020 \mathrm{~nm}$.

Medidas de extinção solar (absorção) são utilizadas de acordo com o algoritmo AERONET AOD em cada comprimento de onda. O expoente Angstrom $(\alpha)$ pode ser recuperado a partir de dados espectrais AOD como alternativa à forma habitual de computação de $\alpha$ em dois comprimentos de onda, como utilizado Nwafor et al. 2007, plota AOD contra a no espaço de registro e, em seguida, é feito um ajustamento linear dos dados recuperados para $\alpha$ necessário.

Dados de nível 2.0 de propriedades ópticas de aerossóis foram utilizados neste estudo. Foi utilizado uma série de dados de 2010 a 2014 . A grande densidade de dados utilizados no período torna mais fácil analisar ciclos de distribuição de tendências de AOD. Há algumas lacunas nas tendências devido à ausência ou observações limitadas. O conjunto de dados foi dividido em dois grupos com base nas variações sazonais como usado em algumas literaturas Balarabe et al. (2015) - Kehinde et al. (2012), (P.B, R.W, et al., 2010) da seguinte forma: estação seca e estação chuvosa.

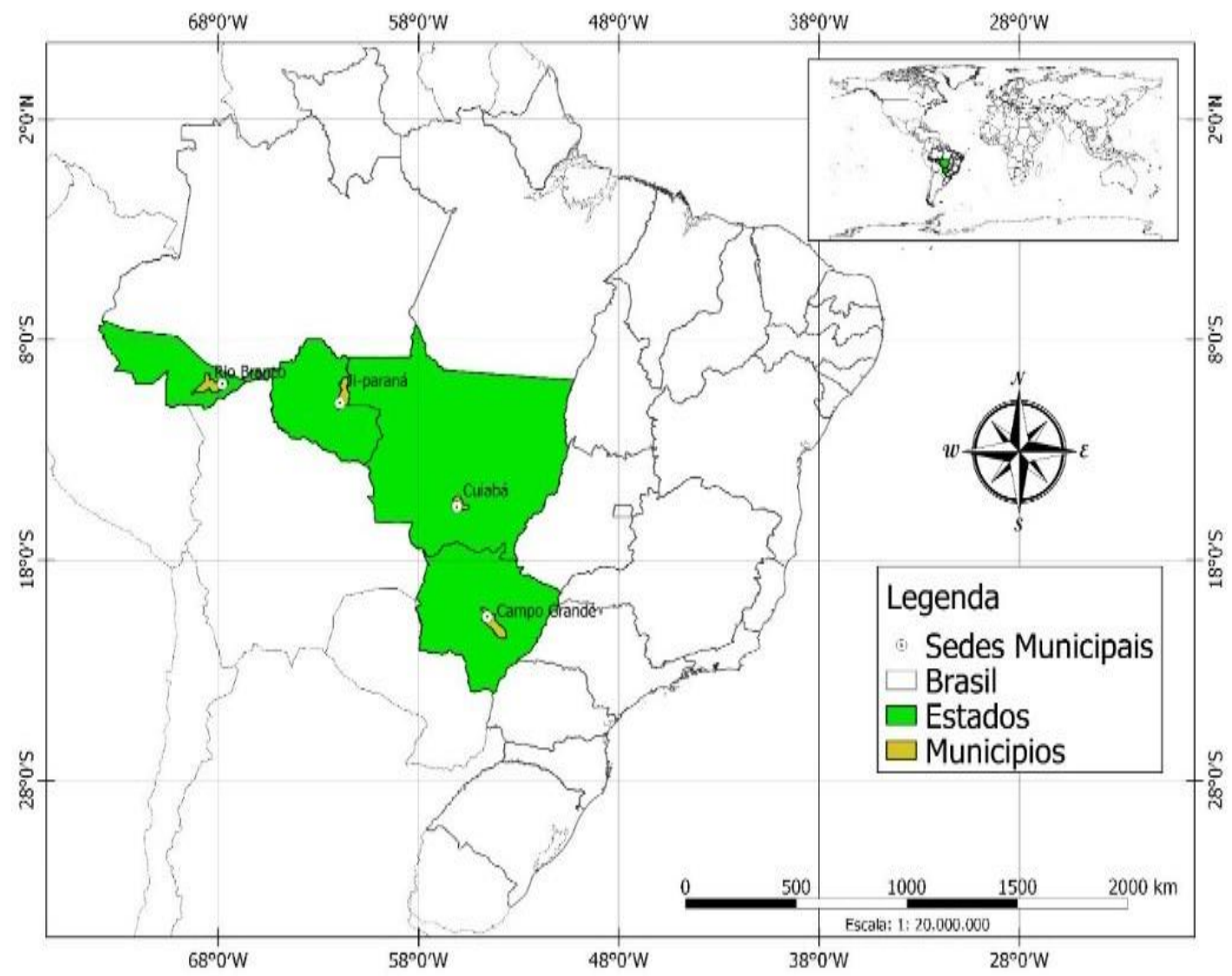

Figura 1 - Regiões geográficas e local dos sítios AERONET usados nesse estudo.

Para apresentar o ciclo mensal de concentração de aerossol para os sítios em estudo, os valores totais de AOD (440 nm) e $\alpha(440-870 \mathrm{~nm})$ foram 
utilizados em toda série de dados. Posteriormente, os dados totais de AOD (440 $\mathrm{nm})$ e $\alpha(440-870 \mathrm{~nm})$ foram analisados para revelar a variabilidade temporal das propriedades ópticas de aerossóis nesses sítios. O padrão sazonal de distribuição de frequências das propriedades ópticas dos aerossóis dos sítios foram identificados por análise espectral de AOD $(440 \mathrm{~nm})$ e $\alpha(440-870 \mathrm{~nm})$ como o usado por Toledano et al. (2007).

As propriedades ópticas acima foram quantitativamente identificadas de acordo com os gráficos de dispersão do Expoente Angstrom $\alpha(440-870 \mathrm{~nm})$ e foram utilizados para a classificação com base nos critérios propostos por (MUKHTAR BALARABE, 2016) e (TOLEDANO, CACHORRO, et al., 2007). Os padrões de distribuição dos diferentes aerossóis foram determinados para os dados gerais e sazonais. Este critério foi aplicado para determinar os tipos de aerossóis para os diferentes tipos de ambientes em estudo, cerrado e floresta.

\section{RESULTADOS E DISCUSSÃO}

\subsection{CLIMATOLOGIA E EVOLUÇÃO TEMPORAL DO AOD EM CERRADO}

A alta resolução temporal dos dados AERONET permite estudar detalhadamente a evolução temporal de AOD (440 nm). Na figura 2 observa-se a variação de AOD (440 nm) para os sítios de Cuiabá e Campo Grande, região de Cerrado. A principal característica de AOD é sua alta variabilidade. Observase que uma série de episódios com AOD no intervalo de 0,5-1,2 ocorre todos os anos nesses sítios. Observa-se que há uma variabilidade ano-a-ano de AOD para a série de dados analisada para o sítio de Cuiabá. A AOD (440 nm) tanto para Cuiabá quanto para Campo Grande, mostra uma tendência decrescente em quase todos os anos.

As variações de AOD (440 nm) para o sítio de Cuiabá observadas na estação seca variam aproximadamente em toda a estação para a série de dados considerada, de 0,5 a 4,5 para o ano de 2010, de aproximadamente 0,3 a 1,4 para o ano de 2011 , de 0,5 a 1,6 para o ano de 2012 e variações de 0,3 a 1,0 para o ano de 2013. A redução de AOD $(440 \mathrm{~nm})$ observada para o sítio de Cuiabá pode estar estreitamente relacionada com mudanças nos padrões climáticos locais. 


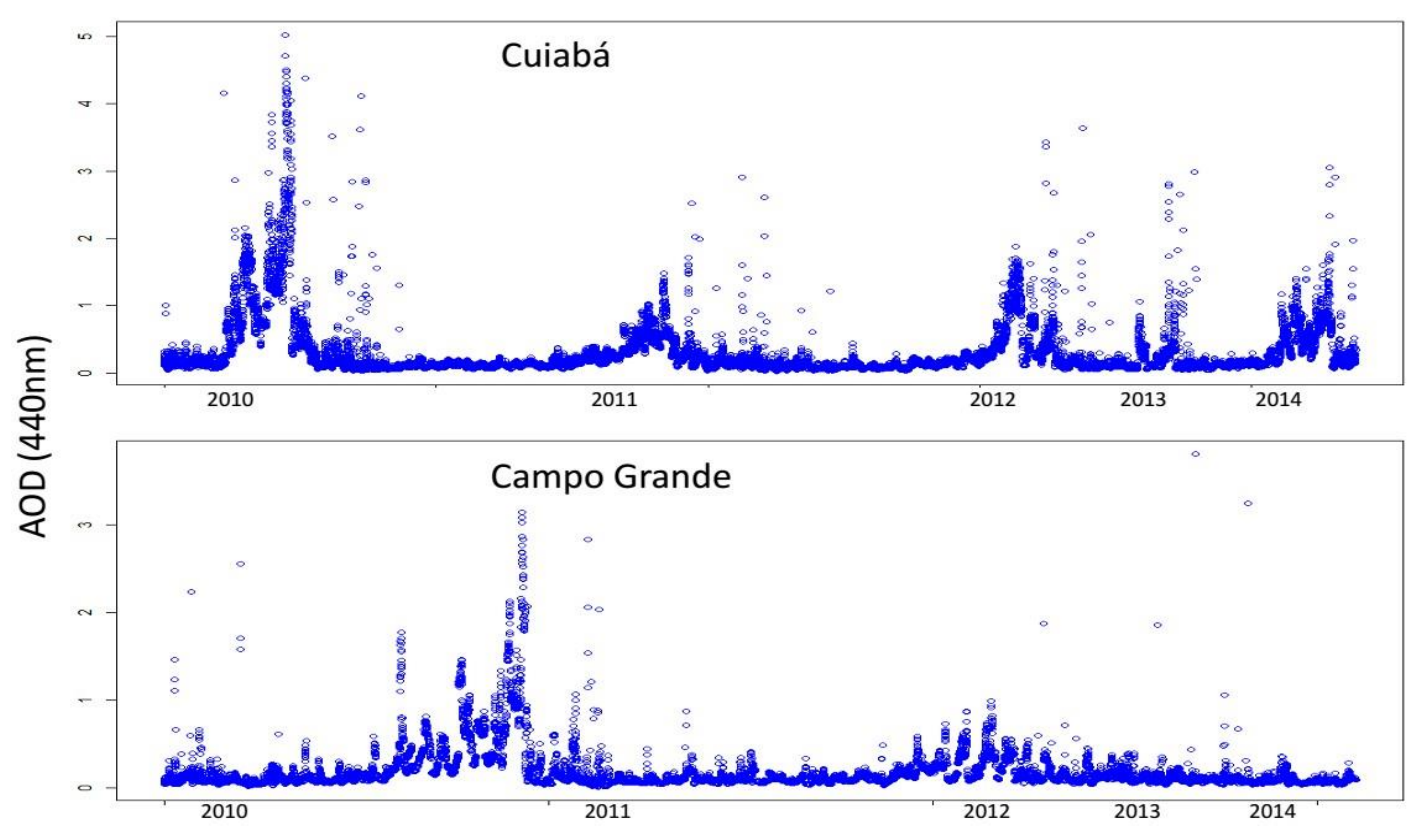

Figura 2 - Profundidade Óptica de Aerossol AOD (440nm) para o sítio de Cuiabá e Campo Grande de 2010 a 2014.

Os aerossóis oriundos de queima de biomassa são os principais responsáveis pela ocorrência desses episódios. A variabilidade é maior para comprimentos de onda menores.

A estatística geral para a série de dados para o sítio de Cuiabá está representada na tabela 1 abaixo. A média de AOD $(440 \mathrm{~nm})$ é 0,29, com desvio padrão de 0,40, representando variações típicas para essas regiões, com máximo de 5,01. A média de AOD diminui para comprimentos de onda maiores, tendo média de AOD (1020 nm) 0,09. Observa-se média de 1,20 para $\alpha$ (440$870 \mathrm{~nm}$ ), com desvio padrão de 0,39 e apresentando máximo de 2,15. Os valores máximos de AOD podem indicar alta variabilidade.

Tabela 1 - Estatística de AOD e expoente Angstrom em todos os comprimentos de onda para série temporal de Cuiabá.

\begin{tabular}{cccccc}
\hline & $\mathrm{AOD}(1020)$ & $\mathrm{AOD}(870)$ & $\mathrm{AOD}(670)$ & $\mathrm{AOD}(440)$ & $\alpha(440-870)$ \\
\hline Média & 0,095 & 0,119 & 0,161 & 0,290 & 1,205 \\
Desvio Padrão & 0,170 & 0,183 & 0,233 & 0,403 & 0,394 \\
Mínimo & 0,006 & 0,013 & 0,015 & 0,025 & 0,246 \\
Máximo & 4,421 & 4,346 & 4,282 & 5,015 & 2,156 \\
Mediana & 0,052 & 0,066 & 0,084 & 0,142 & 1,205 \\
\hline
\end{tabular}

Estatística similar é apresentada na tabela 2 para o sítio de Campo Grande. A média de AOD (440 nm) é 0,18, com desvio padrão de 0,24. Observa-se aumento da média para comprimentos de onda menores, sendo que 
o máximo é observado no comprimento de onda $440 \mathrm{~nm}$, tendo os menores valores relacionados no comprimento de onda $1020 \mathrm{~nm}$. Observa-se média de 1,16 para $\alpha$ (440-870 $\mathrm{nm}$ ), com desvio padrão de 0,36 e apresentando máximo de 2,72 . Os valores máximos de AOD podem indicar alta variabilidade de aerossóis.

Tabela 2 - Estatística de AOD e Expoent Angstrom em todos os comprimentos de onda para série temporal de Campo Grande.

\begin{tabular}{cccccc}
\hline & $\mathrm{AOD}(1020)$ & $\mathrm{AOD}(870)$ & $\mathrm{AOD}(670)$ & $\mathrm{AOD}(440)$ & $\alpha(440-870)$ \\
\hline Média & 0,066 & 0,088 & 0,104 & 0,183 & 1,166 \\
Desvio Padrão & 0,100 & 0,127 & 0,139 & 0,241 & 0,363 \\
Mínimo & 0,001 & 0,009 & 0,008 & 0,014 & 0,295 \\
Máximo & 4,025 & 3,971 & 3,889 & 3,804 & 2,722 \\
Mediana & 0,043 & 0,050 & 0,063 & 0,107 & 1,174 \\
\hline
\end{tabular}

A alta qualidade e precisão das observações AERONET fornece uma boa oportunidade de investigação de mudanças de AOD e o que faz com que ocorram. Histogramas de frequência de $\alpha(440-870 \mathrm{~nm})$ para os sítios de Cuiabá e Campo Grande são plotados na figura 3, mostrando diferentes modos de frequência. Observa-se um modo de frequência específico para cada sítio analisado. Para Cuiabá o modo de frequência especifico está centralizado em torno de 1,2, e Campo Grande com modo de frequência centralizado em torno de 1,1 .
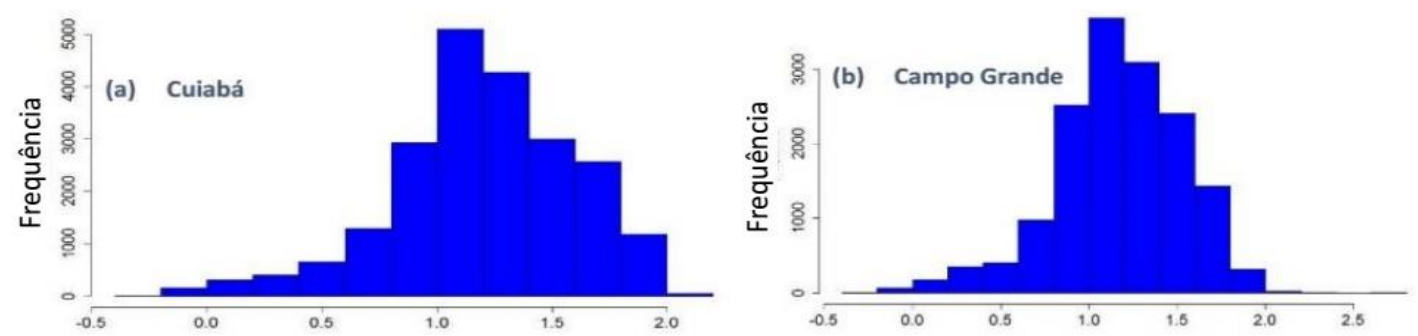

Figura 3 - Histograma de frequência para $\alpha$ (440-870) para (a) Cuiabá e (b) Campo Grande.

A evolução temporal de $\alpha$ para o sítio de Cuiabá e Campo Grande para o período de 2010-2014 é apresentado na figura 4. Observa-se que em ambos os sítios se tem alta variabilidade, com valores na faixa de 0 a 2 ao longo de toda a série de dados. Não se observa valores negativos ao longo da série, que se relacionam com dias nublados e provavelmente com contaminação com nuvem para ambos os sítios. Pelo contrário, durante a estação seca os valores de AOD mais altos, acima de 0,2, em média, resultam em valores recuperados mais precisos, permitindo a identificação e monitoramento de eventos com alto AOD e baixo $\alpha$ e eventos relacionados com alto AOD e alto $\alpha$. 


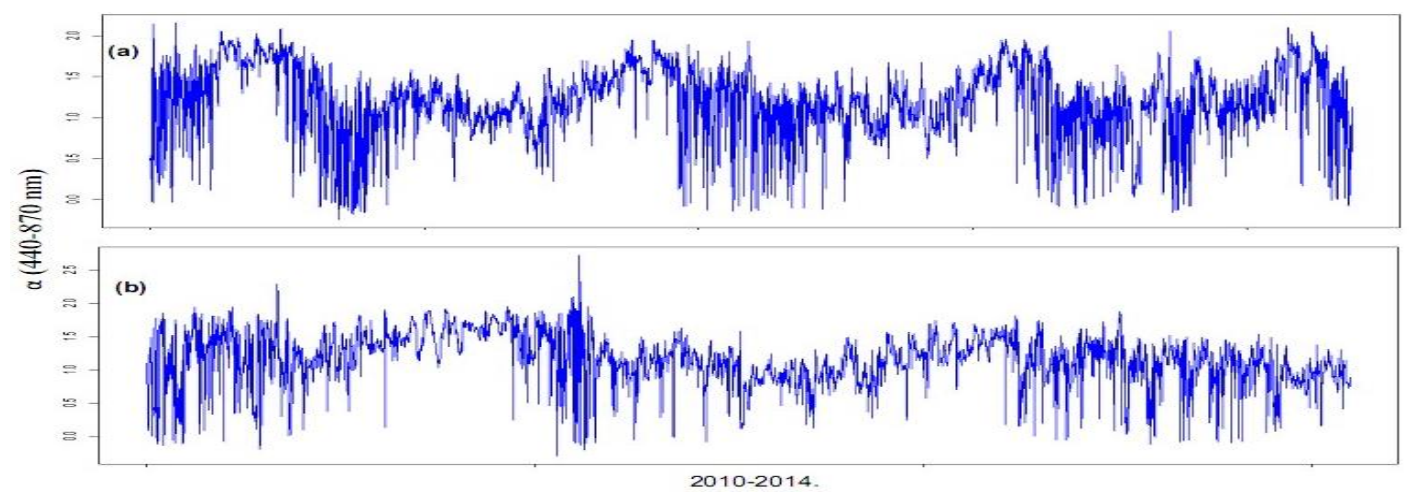

Figura 4 - Evolução Temporal Expoente Angstron, $\alpha$ para (a) Cuiabá e (b) Campo Grande de 2010-2014.

A variação da média diária de AOD (440 nm) e $\alpha(440-870 \mathrm{~nm})$ são apresentados para estabelecer as diferenças climatológicas sobre os sítios de Cerrado (Cuiabá e Campo Grande). Na figura 5 a variabilidade da média diária de AOD $(440 \mathrm{~nm})$ e $\alpha(440-870 \mathrm{~nm})$ é retratada. Observa-se pequena variação diária para os sítios de Cerrado (Cuiabá e Campo Grande), exceto para os períodos relacionados a queima de biomassa, quando a AOD (440 nm) e $\alpha$ (440$870 \mathrm{~nm}$ ) podem assumir valores extremamente elevados.
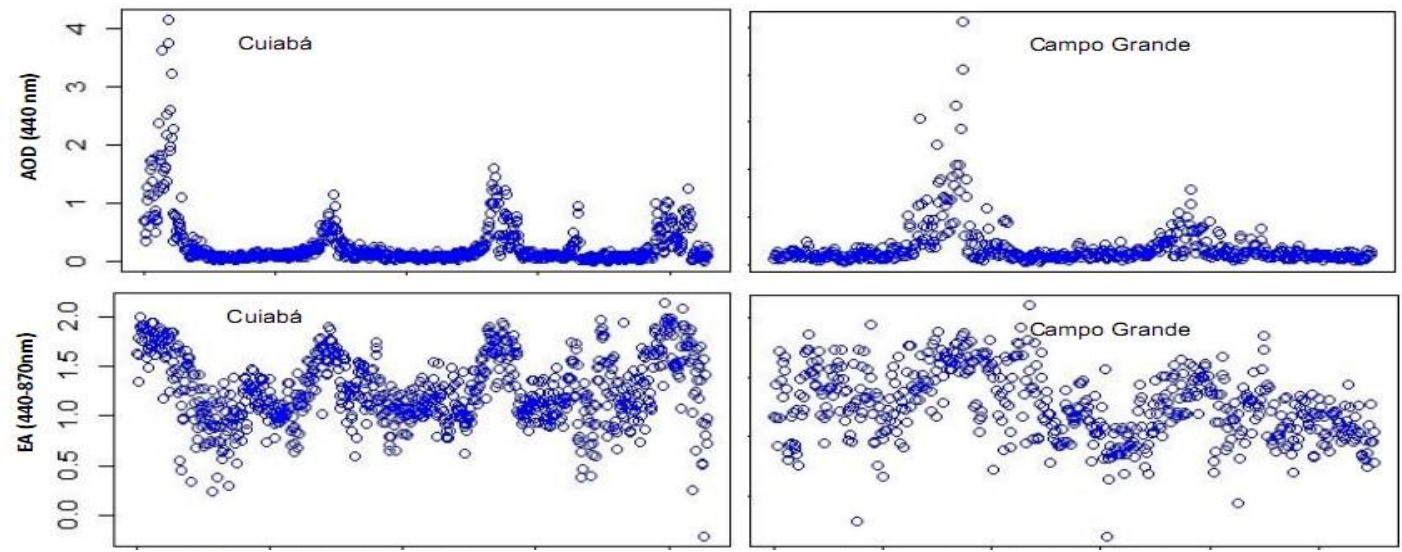

Figura 5 - Média diária de $\operatorname{AOD}(440 \mathrm{~nm})$ e Expoente Angstron (440-870 nm) para (a) Cuiabá e (b) Campo Grande para o período de 2010-2014.

Uma vez que as principais características das medições individuais foram observadas, diariamente, médias mensais de AOD foram calculadas de modo a obter valores para a climatologia do AOD (440 nm). A figura 6 mostra a média mensal para o canal $440 \mathrm{~nm}$ para o período de 2010 a 2014 para os sítios de Cuiabá e Campo Grande. A variabilidade é indicada pelo desvio padrão mensal. Observa-se máximos de AOD durante a estação seca para o sítio de Cuiabá e Campo Grande. Há redução de AOD de dezembro a julho no sítio de Cuiabá, padrão de diminuição após a estação seca, tendo elevação de AOD (440 nm) durante os meses de agosto a novembro sendo consistente com toda série de 
dados. Para o sitio de Campo Grande têm-se leve aumento de AOD na estação seca, com redução em toda estação chuvosa em toda série de dados.
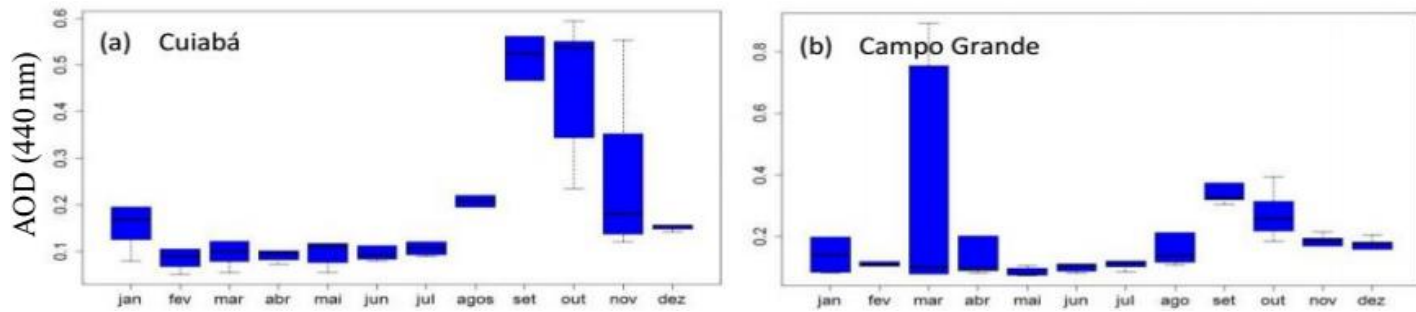

Figura 6 - Média mensal de AOD (440 nm) para (a) Cuiabá e (b) Campo Grande para o período de 2010-2014.

A variabilidade sazonal para os sítios de Cuiabá e Campo Grande podem ser analisadas pelas médias mensais de $\alpha(440-870 \mathrm{~nm})$ apresentados na figura 7 (também Tabela 1 e 2). As diferenças de valores mensais de $\alpha(440-870 \mathrm{~nm})$ ao longo dos anos para o sítio de Cuiabá são crescentes, considerando que os maiores valores são observados entre os meses de agosto a outubro. Para o sítio de Campo Grande as diferenças de valores mensais ao longo dos anos são pequenas.

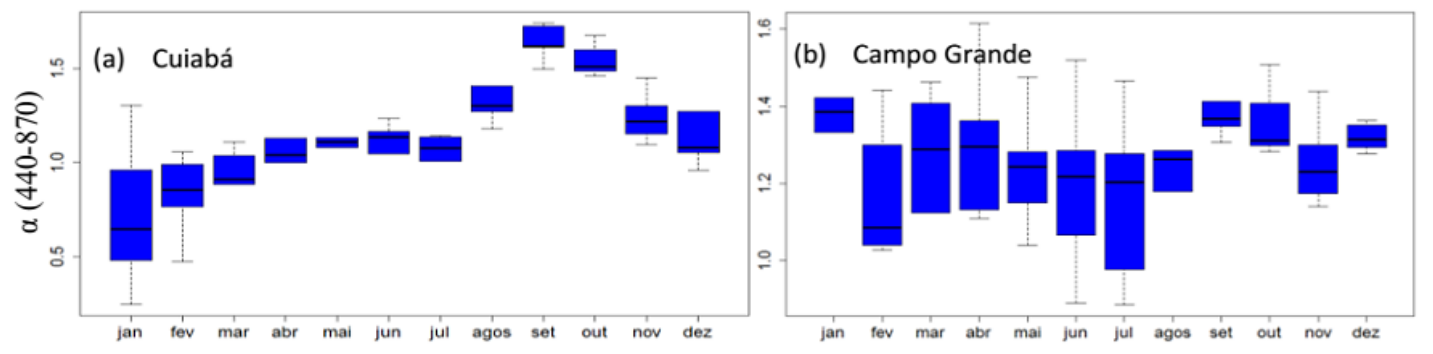

Figura 7 - Média mensal de Expoente Angstron (440-870 nm) para (a) Cuiabá e (b) Campo Grande para o período de 2010-2014.

\subsection{CLIMATOLOGIA E EVOLUÇÃO TEMPORAL DO AOD EM FLORESTA}

A figura 8 mostra a variação de AOD (440 nm) para sítio de Rio Branco e Ji-Paraná, região de Floresta. Há uma série de episódios com AOD (440 nm) no intervalo de $0,1-1,8$ que ocorre todos os anos para os sítios de Rio Branco e JiParaná. Observa-se ainda variabilidade ano-a-ano de AOD para a série de dados analisada para o sítio de Rio Branco. A AOD (440 nm) na região de floresta, mostra uma tendência constante para o sítio de Rio Branco (AC) e decrescente para a série de dados analisadas para o sítio de Ji-Paraná (RO). 


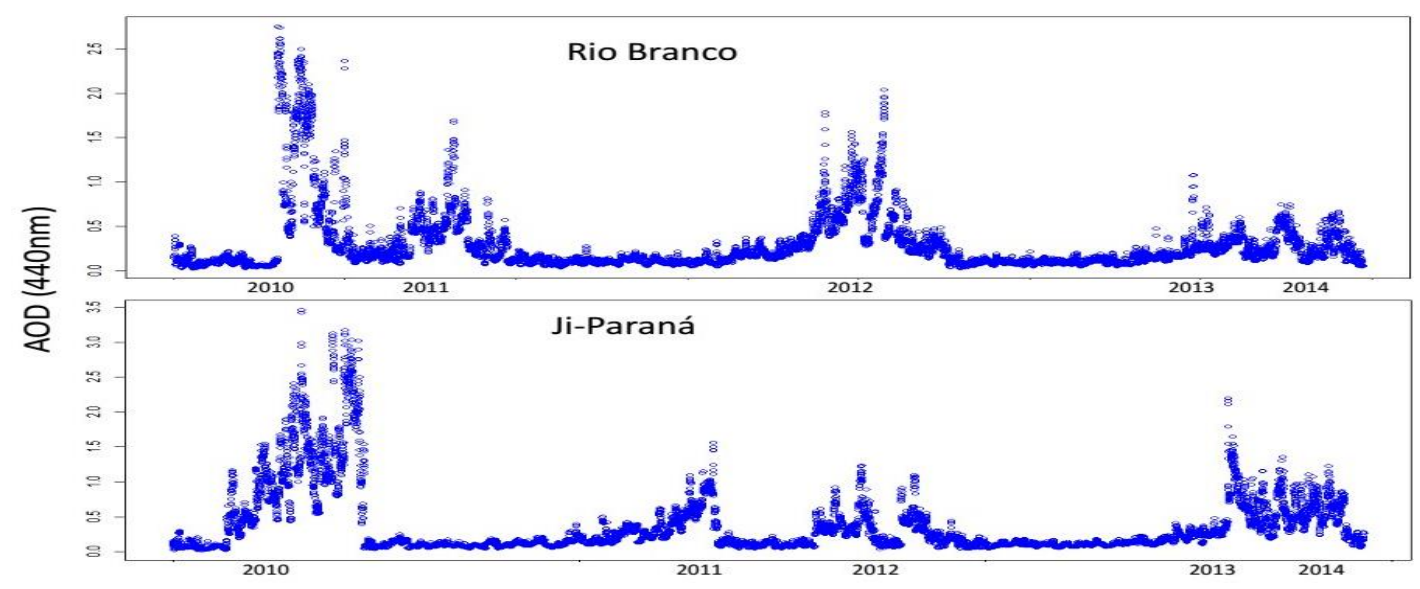

Figura 8 - Profundidade Óptica de Aerossol AOD (440nm) para o sítio de Rio Branco e JiParaná de 2010 a 2014.

As variações de AOD (440 nm) para o sítio de Rio Branco (AC) observadas na estação seca variam aproximadamente em toda a estação para a série de dados considerada, de 0,4 a 2,6 para o ano de 2010, de aproximadamente 0,3 a 1,6 para o ano de 2011 , de 0,5 a 1,6 para o ano de 2012 e variações de 0,4 a 2,0 para o ano de 2013 e, com pequenas variações para o ano de 2014, variando de 0,6 a 1,1. A redução de AOD $(440 \mathrm{~nm})$ observada para o sítio de Ji-Paraná (RO) pode estar também relacionada com mudanças nos padrões climáticos locais.

A estatística descritiva para a série de dados do sítio de Rio Branco (RO) está representada na tabela 3 . A média de AOD $(440 \mathrm{~nm})$ é 0,85 . O desvio padrão de AOD (440 nm) é 0,71, representando variações típicas para essas regiões, com máximo de 4,24. A média de AOD (440 nm) diminui para comprimentos de onda maiores, tendo média de AOD (1020 nm) 0,08. Observase a média de 1,39 para $\alpha$ (440-870nm), com desvio padrão de 0,41, apresentando máximo de 2,25 Os valores máximos de AOD podem indicar alta variabilidade de aerossóis.

Tabela 3 - Estatística de AOD e Expoente Angstrom em todos os comprimentos de onda para série temporal de Rio Branco.

\begin{tabular}{cccccc}
\hline & $\mathrm{AOD}(1020)$ & $\mathrm{AOD}(870)$ & $\mathrm{AOD}(670)$ & $\mathrm{AOD}(440)$ & $\alpha(440-870)$ \\
\hline Média & 0,080 & 0,099 & 0,145 & 0,851 & 1,389 \\
Desvio Padrão & 0,123 & 0,138 & 0,185 & 0,715 & 0,415 \\
Mínimo & 0,003 & $-0,002$ & 0,013 & 0,083 & 0,291 \\
Máximo & 4,215 & 4,205 & 4,210 & 4,241 & 2,249 \\
Mediana & 0,050 & 0,060 & 0,086 & 0,599 & 1,462 \\
\hline
\end{tabular}

A média de AOD (440 nm) para o sítio de Ji-Paraná (RO) é de 0,35, conforme tabela 4. Desvio padrão de AOD $(440 \mathrm{~nm})$ de 0,44 , com máximo de 3,45. A média de AOD (440 $\mathrm{nm}$ ) diminui para comprimentos de onda maiores, tendo média de AOD (1020 nm) 0,09. Observa-se média de 1,40 para $\alpha$ (440- 
$870 \mathrm{~nm}$ ), com desvio padrão de 0,34 , apresentando máximo de 2,21. Os valores máximos de AOD podem indicar tendência de alta variabilidade nessa região.

Tabela 4 - Estatística de AOD e expoente Angstrom em todos os comprimentos de onda para série temporal de Ji-Paraná (RO).

\begin{tabular}{cccccc}
\hline & $\mathrm{AOD}(1020)$ & $\mathrm{AOD}(870)$ & $\mathrm{AOD}(670)$ & $\mathrm{AOD}(440)$ & $\alpha(440-870)$ \\
\hline Média & 0,090 & 0,120 & 0,176 & 0,353 & 1,400 \\
Desvio Padrão & 0,097 & 0,131 & 0,221 & 0,441 & 0,347 \\
Mínimo & 0,002 & 0,011 & 0,007 & 0,020 & 0,107 \\
Máximo & 1,296 & 1,493 & 1,944 & 3,459 & 2,215 \\
Mediana & 0,054 & 0,068 & 0,085 & 0,159 & 1,403 \\
\hline
\end{tabular}

Histogramas de frequência de $\alpha(440-870 \mathrm{~nm})$ para os sítios de Ji-Paraná (RO) e Rio Branco (AC) são plotados na figura 9 abaixo, mostrando diferentes modos de frequência. Observa-se um modo de frequência específico para cada sítio analisado. Para Rio Branco o modo de frequência especifico está centralizado em torno de 1,8 e Ji-Paraná com modo de frequência centralizado em torno de 1,4
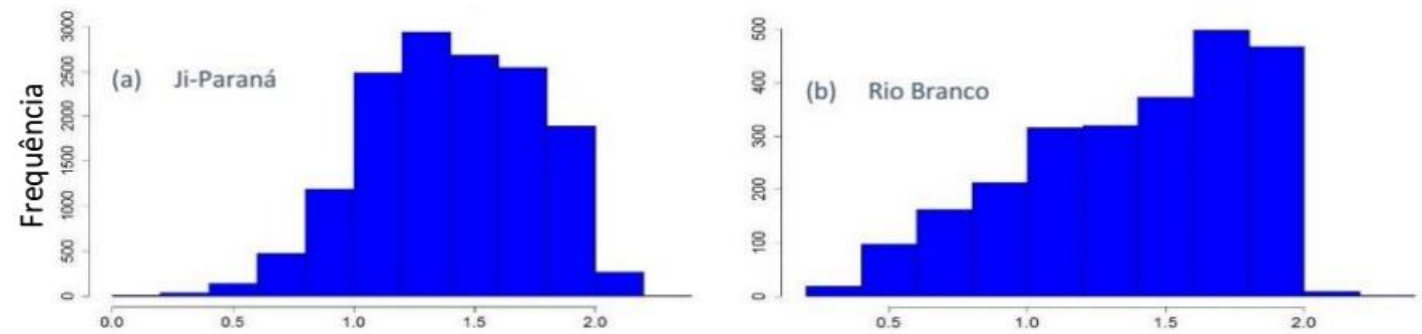

Figura 9 - Histograma de frequência para a (440-870) para (a) Ji-Paraná e (b) Rio Branco.

A evolução temporal de $\alpha(440-870 \mathrm{~nm})$ para o sítio de Rio Branco (AC) e Ji-Paraná (RO) para o período de 2010-2014 é apresentado na figura 10. Observa-se maior variabilidade no sítio de Rio Branco (AC), com valores na faixa de 0 a 2,3 ao longo de toda a série de dados. Em ambos os sítios se observa eventos com alto AOD (440 $\mathrm{nm})$ e baixo $\alpha(440-870 \mathrm{~nm})$, com eventos de alto AOD $(440 \mathrm{~nm})$ e alto $\alpha(440-870 \mathrm{~nm})$ relacionado. 


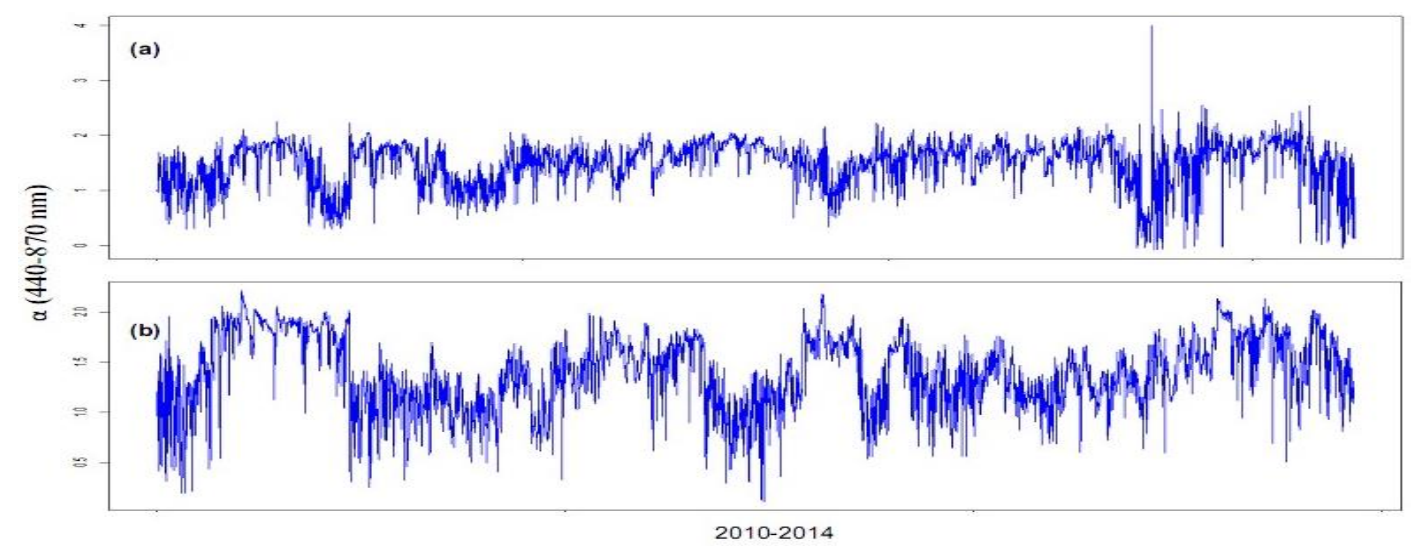

Figura 10 - Evolução Temporal do Expoent Angstrom, a para (a) Rio Branco e (b) JiParaná de 2010-2014.

A variação da média diária de AOD (440 nm) e $\alpha(440-870 \mathrm{~nm})$ são apresentados para estabelecer as diferenças climatológicas sobre os sítios de Floresta (Rio Branco e Ji-paraná). Na figura 11 a variabilidade da média diária de AOD $(440 \mathrm{~nm})$ e $\alpha(440-870 \mathrm{~nm})$ é retratada. Observa-se também variação diária para os sítios de Floresta (Rio Branco e Ji-Paraná, exceto para os períodos relacionados a queima de biomassa, quando a AOD (440 nm) pode assumir valores extremamente elevados.
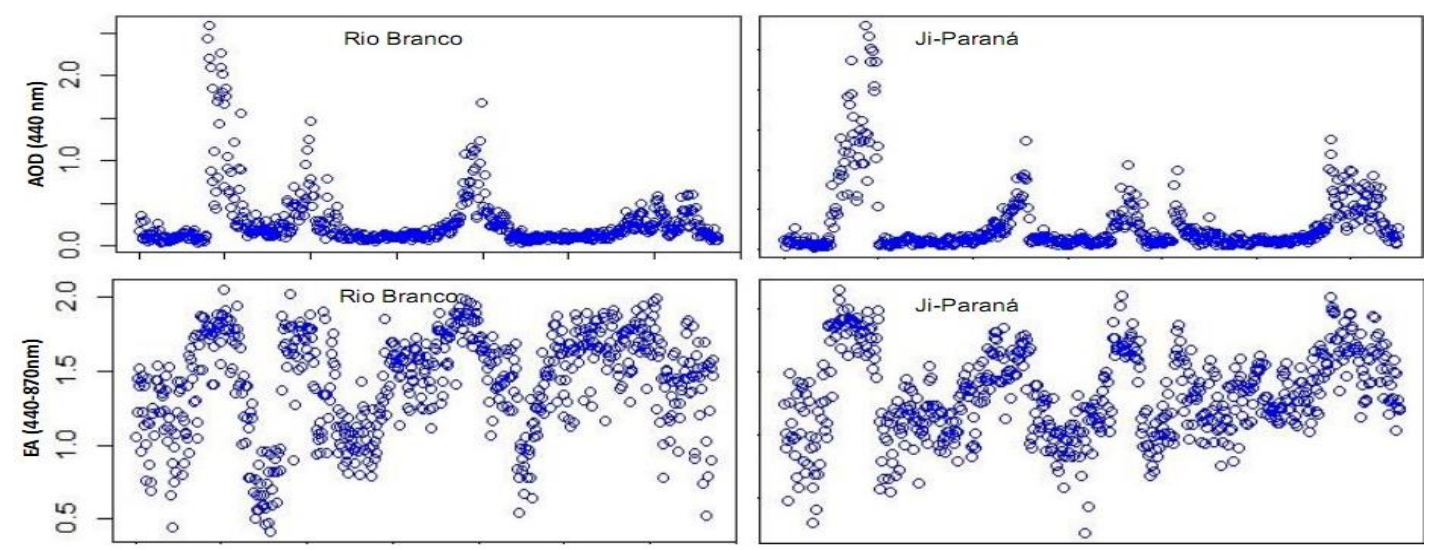

Figura 11 - Média diária de $\operatorname{AOD}(440 \mathrm{~nm})$ e Expoente Angstron (440-870 nm) para (a) Rio Branco e (b) Ji-Paraná para o período de 2010-2014.

Observa-se máximos de AOD (440 nm) durante a estação seca, figura 12, sendo que para o sítio de Rio Branco (AC) observa-se maiores valores de AOD concentrados nos meses de setembro e outubro. Para o sítio de Ji-Paraná os maiores valores na estação seca concentram-se no mês de outubro, com padrão de diminuição de dezembro a julho. 

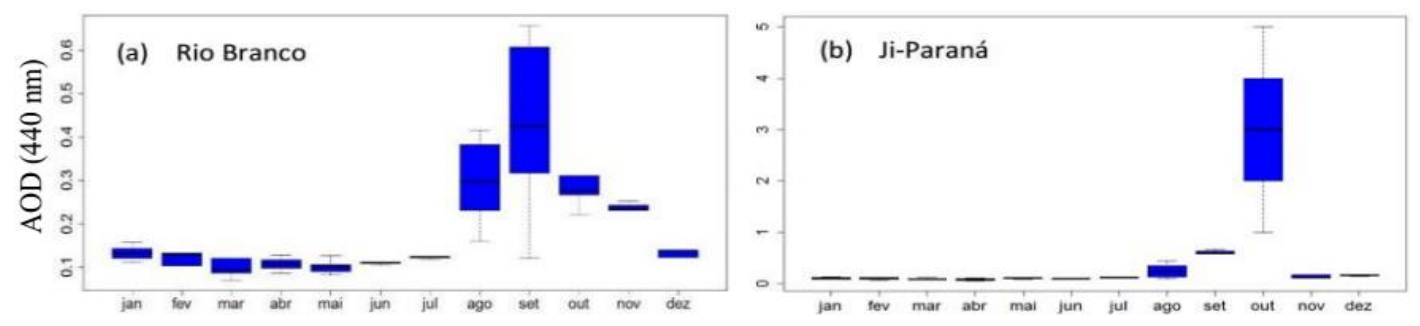

Figura 12 - Média mensal de AOD (440 nm) para (a) Rio Branco e (b) Ji-Paraná para o período de 2010-2014.

A variabilidade sazonal para os sítios de Rio Branco (AC) e Ji-Paraná (RO) podem ser analisadas pelas médias mensais de $\alpha(440-870 \mathrm{~nm})$ apresentados na figura 13 abaixo (também Tabela 3 e 4). As diferenças de valores mensais ao longo dos anos para o sítio de Rio Branco (AC) são crescentes, considerando que os maiores valores são observados entre os meses de maio a setembro. Para o sítio de Ji-Paraná (RO) as diferenças de valores mensais ao longo dos anos são crescentes, tendo os maiores valores compreendidos entre os meses de agosto a outubro.
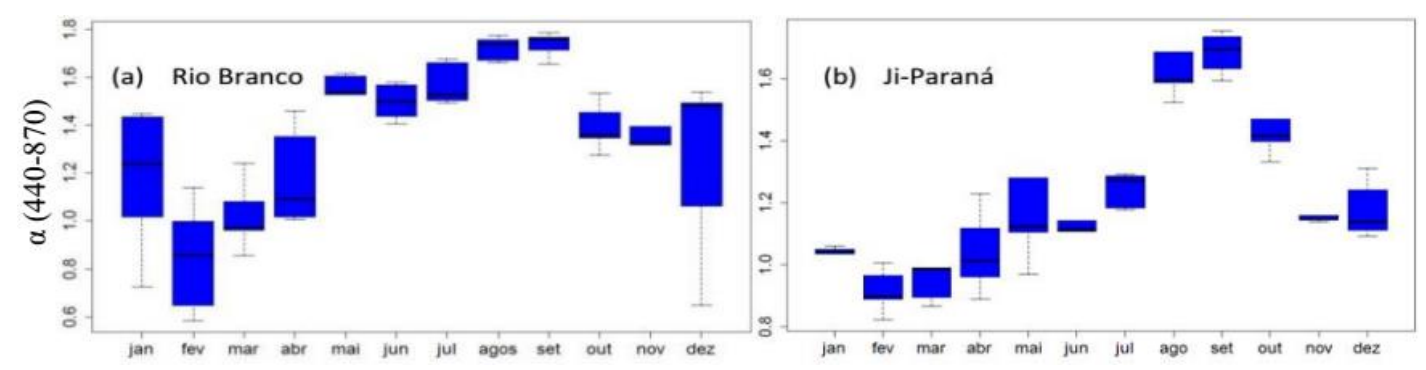

Figura 13 - Média mensal de $\alpha(440-870 \mathrm{~nm}$ ) para (a) Rio Branco e (b) Ji-Paraná para o período de 2010-2014.

\subsection{CLIMATOLOGIA E EVOLUÇÃO TEMPORAL DO EXPOENTE ANGSTROM EM CERRADO}

O gráfico de dispersão a (440-870 nm) - AOD (440 nm) é uma ferramenta comum para classificar e caracterizar os tipos de aerossóis conforme Toledano et al. (2007). Enquanto o AOD dá informações sobre a quantidade de aerossóis, $\alpha$ (440-870 nm) relaciona-se com o tamanho do aerossol (tipo), a análise conjunta de ambos os parâmetros torna possível uma melhor interpretação dos dados.

Com análise espectral, de aerossóis de floresta e cerrado, é possível a identificação dos principais tipos de aerossóis, bem como avaliar a frequência de cada tipo de aerossol presente. Sendo assim, foram feitos gráficos de dispersão de $\alpha(440-870 \mathrm{~nm})$ contra AOD (440nm), para estação seca e chuvosa, sendo apresentados na figura 14 abaixo para o sítio de Cuiabá e Campo Grande. As escalas de cores nos gráficos indicam o número de medidas realizadas em diferentes estações. 

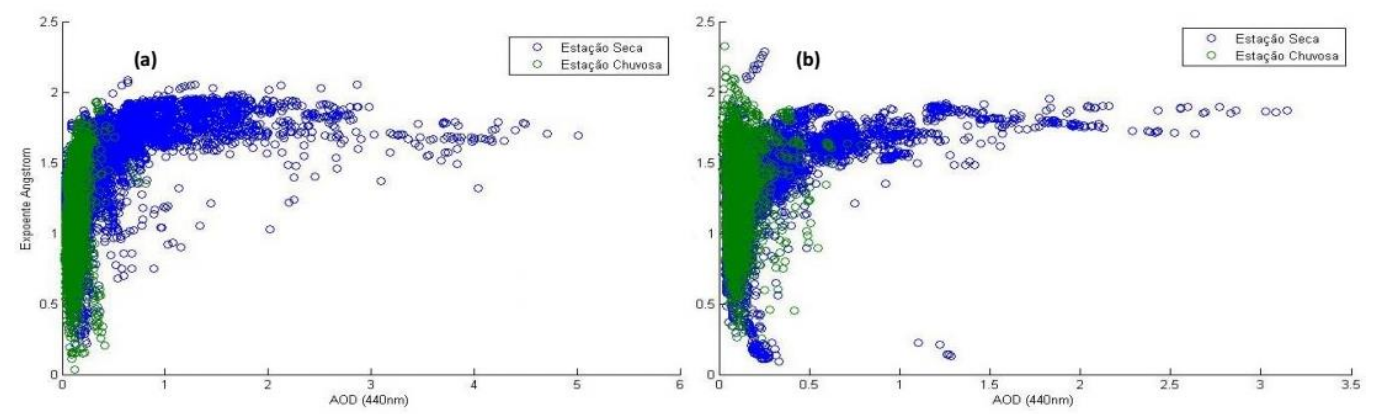

Figura 14 - Expoente Angstrom versus AOD para estação seca e chuvosa para sítio de (a) Cuiabá e (b) Campo Grande.

Quando AOD (440 nm) é baixo tem-se valores de $\alpha(440-870 \mathrm{~nm})$ sobre todo alcance, porém, principalmente concentrado em torno de uma região de 0,2-1,7. Assim, pode-se observar baixos valores de AOD (440 nm) na estação chuvosa para o sítio de Cuiabá e Campo Grande.

Na estação seca observa-se um crescimento progressivo dos valores de AOD (440 nm) para ambos os sítios. Para os maiores valores de AOD (440 nm), a situação é mais definida; $\alpha$ (440-870 nm) está compreendido abaixo ou acima de 1,5 . A análise desses ambientes revela a presença de diferentes tipos de aerossóis.

\subsection{CLIMATOLOGIA E EVOLUÇÃO TEMPORAL DO EXPOENTE ANGSTROM EM FLORESTA}

Para o sítio de Rio Branco (AC), conforme figura 15, observa-se baixos valores de AOD (440 nm) para estação seca com crescimento progressivo dos valores de $\alpha$ (440-870 nm). Os maiores eventos observados para a estação seca nesse sítio concentram-se em valores de AOD $(440 \mathrm{~nm})$ compreendidos entre 0,1-0,5 com $\alpha(440-870 \mathrm{~nm})$ entre $0,4-1,7$. Na estação chuvosa tem-se altos valores de AOD (440 nm) associados com crescimento progressivo de valores de $\alpha(440-870 \mathrm{~nm})$. Os maiores eventos observados na estação seca indicam altos valores de AOD (440nm) entre $0,1-2,5$, sendo que a maior concentração de dados está entre valores de AOD (440 nm) que variam de 0,1-1,0.
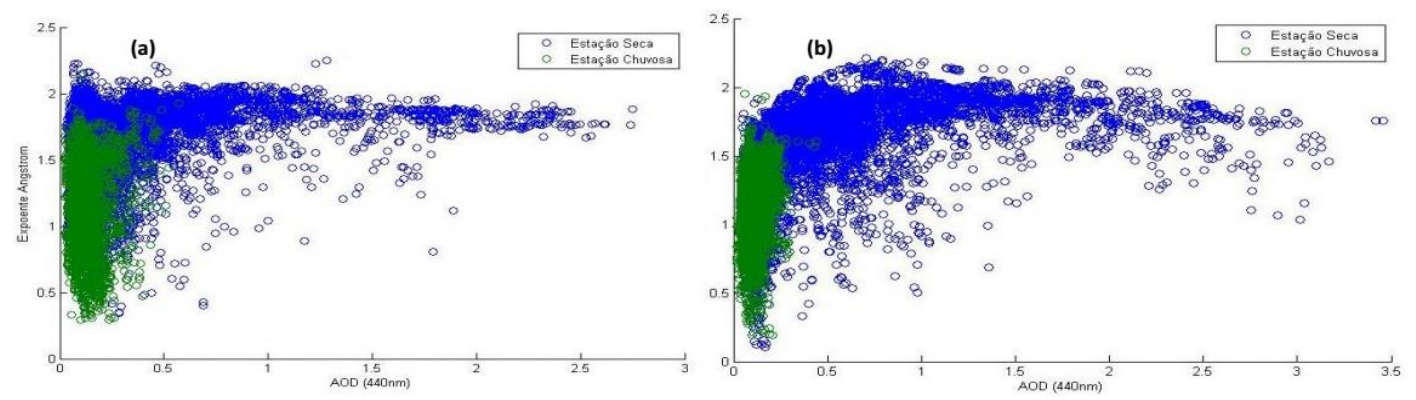

Figura 15 - Expoente Angstrom versus AOD para estação seca e chuvosa para sítio de (a) Rio Branco e (b) Ji-Paraná.

No sítio de Ji-Paraná (RO) os maiores episódios para a estação seca ocorrem com valores de AOD (440 nm) de aproximadamente 2,7 associados 
com $\alpha(440-870 \mathrm{~nm})=2,4$. Na estação chuvosa observa-se valores de AOD de 0,4 associados com $\alpha(440-870 \mathrm{~nm})=1,7$.

\subsection{CLASSIFICAÇÃO DE AEROSSOL: AOD (440 nm) VERSUS EA (440-870 nm) EM CERRADO}

Os produtos de AOD $(440 \mathrm{~nm})$ e $\alpha(440-870 \mathrm{~nm})$ podem prover informações sobre características de absorção e extinção e distribuição de tamanho de aerossóis na atmosfera. Em geral, altos valores de AOD estão associados a alta extinção (absorção) da radiação, e pelas mesmas razões, altos valores de $\alpha$ (440-870 nm) estão associados a distribuição de tamanho de aerossóis de moda fina. Essas duas características são consideradas a assinatura de aerossóis de queima de biomassa.

A análise do espectro de AOD (440 $\mathrm{nm}$ ) versus $\alpha(440-870 \mathrm{~nm})$, figura 16, permite a identificação dos principais tipos de aerossóis presentes nos sítios de Cuiabá e Campo Grande. No sítio de Cuiabá existe uma vasta gama de valores $\alpha(440-870 \mathrm{~nm})$ inferiores a $0,5 \mathrm{com}$ baixo AOD $440 \mathrm{~nm}(<0,4)$ observados na estação chuvosa, podendo ser caracterizados como poeira em suspensão.
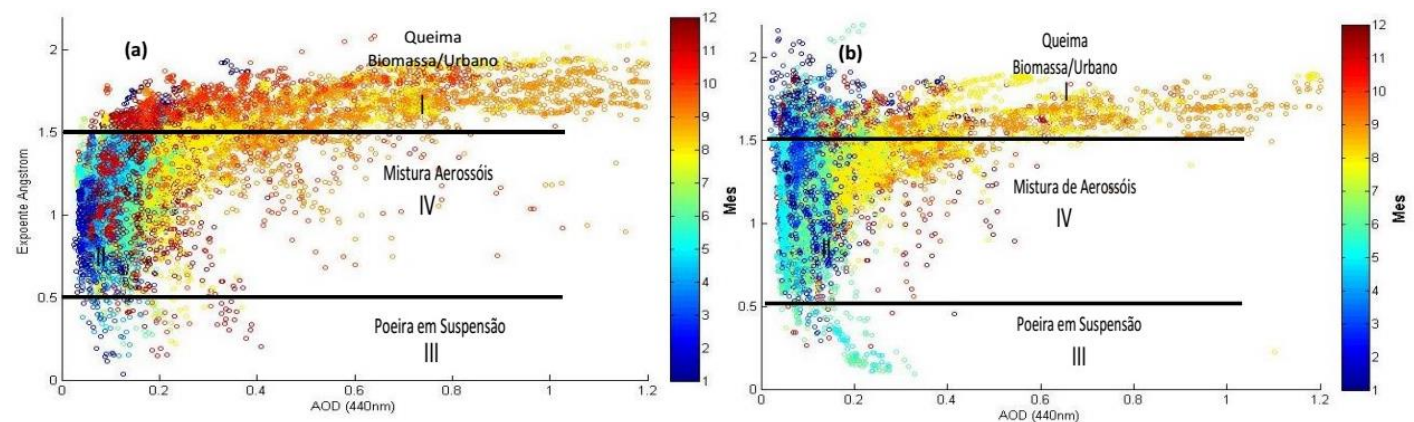

Figura 16 - Gráfico Expoente Angstrom versus AOD(440nm) para (a) Cuiabá e (b) Campo Grande.

Ainda na estação seca, observa-se valores de $\alpha$ (440-870 nm) compreendidos entre 0,5 e 1,5 referente a mistura de aerossóis característicos desses sítios, sendo que os valores crescentes de $\alpha(440-870 \mathrm{~nm})$ com 0 aumento significativo da AOD $(440 \mathrm{~nm})$ indicam contribuição de finas partículas na coluna atmosférica (D. G. KASKAOUTIS et al., 2007). Uma relação semelhante entre concentração de partículas (através de AOD) e tamanho de partícula (por meio Expoente Angstrom) foi observada para uma variedade de aerossóis de moda fina (REMER, KAUFMAN, et al., 1998).

Para os valores observados na estação seca de $\alpha(440-870 \mathrm{~nm})$ superiores a 1,5 e AOD $(440 \mathrm{~nm})(<1,2)$, tem-se aerossóis oriundos de queima de biomassa e/ou aerossóis urbanos e/ou áreas industriais, sendo que tais eventos são mais intensos no sítio de Campo Grande.

Para o sítio de Campo Grande observa-se que o maior número de medidas se concentra aproximadamente na região de AOD $(440 \mathrm{~nm})$ entre 0,2 e 0,4 e $\alpha$ entre 0,5 e 1,7. Nas regiões de Cerrado com alta densidade de dados, quando AOD está abaixo de 0,1 encontramos valores de $\alpha(440-870 \mathrm{~nm})$ na 
faixa de 0,55-1,65. Por outro lado, quando AOD está entre 0,1 e 0,2 a faixa de $\alpha$ (440-870 nm) está compreendida entre 1-1,5.

Assim, para o sítio de Campo Grande (figura 16b) os valores de $\alpha$ (440$870 \mathrm{~nm}$ ) inferiores 0,5 e com baixo AOD $(440 \mathrm{~nm})(<0,4)$ observados na estação chuvosa, podem ser caracterizados como poeira em suspensão. Para os valores de $\alpha$ (440-870 nm) compreendidos entre 0,5 e 1,5, na estação chuvosa, tem-se mistura de aerossóis característicos desses sítios, sendo que os valores crescentes de $\alpha(440-870 \mathrm{~nm})$ com o aumento significativo da AOD (440 nm) indicam contribuição de finas partículas nesse ambiente. É possível ainda observar que para a estação seca, valores de $\alpha(440-870 \mathrm{~nm})$ superiores a 1,5 com AOD $(440 \mathrm{~nm})(<1,2)$ corresponde a aerossóis oriundos de queima de biomassa e/ou aerossóis urbanos e/ou de aéreas industriais.

\subsection{CLASSIFICAÇÃO DE AEROSSOL: AOD (440 nm) VERSUS EA (440-870 nm) EM FLORESTA}

A figura 17 indica claramente, sítio de Ji-Paraná, que o maior número de medidas está concentrado na região de AOD entre 0,1 e 1,0 e $\alpha(440-870 \mathrm{~nm})$ entre 0,5 e 2,0. Os eventos de alto AOD (440 nm) (até 1,1 em $440 \mathrm{~nm}$ ) com altos valores de $\alpha(440-870 \mathrm{~nm})$ associado acima de 1,5 na figura 17 estão relacionadas com os incêndios florestais durante o verão (estação seca). Assim, observa-se para o sítio de Ji-Paraná (RO) e Rio Branco (AC) incidências significativas relacionadas a eventos de queimadas na estação seca. O episódio mais importante para o sítio de Ji-Paraná é observado nos meses de setembro e outubro, com um máximo de AOD (440 nm) aproximadamente de 1,2 e $\alpha$ (440$870 \mathrm{~nm})=1,85$ associado.

Assim, para o sítio de Ji-Paraná (figura 16a) os valores de $\alpha$ (440-870 $\mathrm{nm}$ ) superiores a 1,5 correspondem a aerossóis oriundos de queima de biomassa e/ou aerossóis urbanos e/ou de aéreas industriais, sendo que tais eventos são observados para a estação seca no período compreendido entre os meses de setembro a novembro. Os valores de a (440-870 nm) compreendidos entre 0,5 e 1,5 observado pode ser classificado como mistura de aerossóis para valores de AOD superiores a 0,8 , e são observados durante a estação seca. Para a estação chuvosa, observa-se valores de $\alpha(440-870 \mathrm{~nm})$ inferiores a 0,5 com AOD $(440 \mathrm{~nm})(<0,2)$ que podem ser caracterizados como aerossóis oriundos de poeira em suspensão.
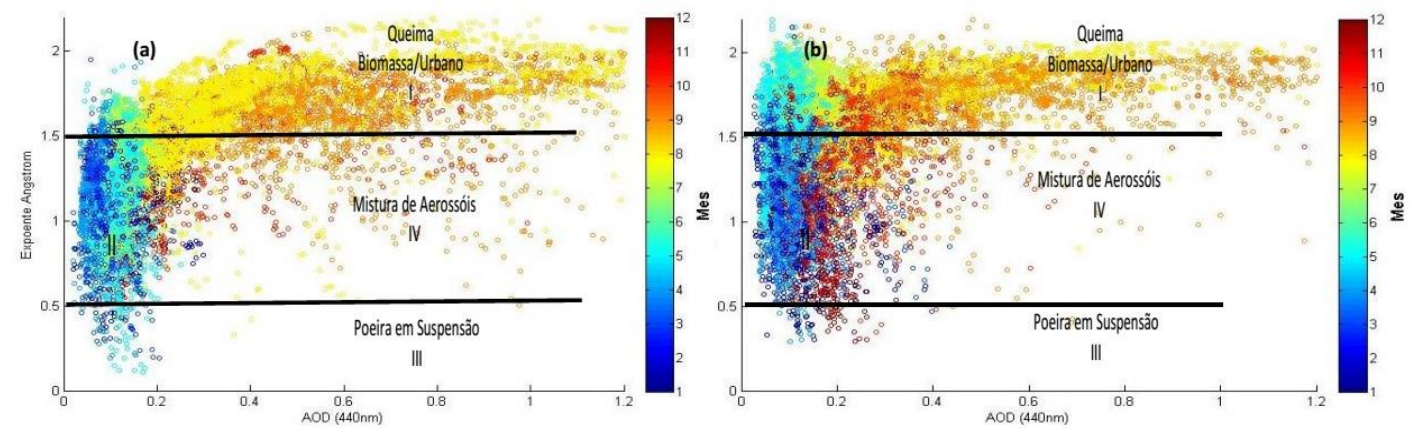

Figura 17 - Gráfico AOD (440nm) versus Expoente Angstrom para (a) Ji-Paraná e (b) Rio Branco. 
Para o sítio de Rio Branco (figura 16b) observa-se que o maior número de medidas se concentra na região de AOD entre 0,1 e 0,5 e $\alpha(440-870 \mathrm{~nm})$ entre 0,5 e 2,1. O episódio mais importante observado aconteceu nos meses de setembro e outubro de 2011, como um máximo de AOD (440 nm) de 1,1 e $\alpha$ $(440-870 \mathrm{~nm})=2,25$ associado.

Assim, para o sítio de Rio Branco os valores de $\alpha(440-870 \mathrm{~nm})$ superiores a 1,5 correspondem também a aerossóis oriundos de queima de biomassa e/ou aerossóis urbanos e/ou de aéreas industriais, sendo que tais eventos são observados para a estação seca no período compreendido entre os meses de setembro a novembro. É possível ainda observar que a densidade desses particulados é mais intensa no sítio de Ji-Paraná (RO) do que no de Rio Branco (AC).

\section{CONCLUSÃO}

Registros (2010-2014) de AOD (440 nm) e $\alpha(440-870 \mathrm{~nm})$, de dados AERONET, foram usados para estudar as variações sazonais de aerossóis, características e tipos, sob diferentes condições atmosféricas em sítios localizados em áreas de Cerrado (Cuiabá e Campo Grande) e Floresta (Rio Branco e Ji-Paraná). Este estudo mostrou que variações sazonais nos sítios de Cerrado e Floresta resultam em diferentes concentrações de aerossóis, características e tipos dominantes. Baixos valores de AOD $(440 \mathrm{~nm})$ e dependência do comprimento de onda são observados em todos os sítios em estudo na estação chuvosa, tendo valores elevados de AOD (440 nm) em todos os sítios na estação seca.

As médias de AOD (440 nm) para os sítios de Cerrado (Cuiabá e Campo Grande) encontradas foram, respectivamente, $0,29( \pm 0,40), 0,18( \pm 0,24)$, com média correspondente de $\alpha(440-870 \mathrm{~nm}) 1,20( \pm 0,39), 1,16( \pm 0,36)$, indicando maior variabilidade no sítio de Cuiabá. As médias de AOD (440 nm) para os sítios de Floresta (Rio Branco e Ji-Paraná) encontradas foram, respectivamente, $0,85( \pm 0,71), 0,35( \pm 0,44)$, com média correspondente de $\alpha(440-870 \mathrm{~nm})$ $1,38( \pm 0,41), 1,40( \pm 0,34)$, indicando maior variabilidade no sítio de Rio Branco.

A análise do espectro de AOD (440 $\mathrm{nm})$ versus $\alpha(440-870 \mathrm{~nm})$ para os sítios em Cerrado permitiu identificar vasta gama de aerossóis, tendo alta densidade de dados concentrada na faixa de valores de $\alpha(440-870 \mathrm{~nm})$ compreendidos entre 0,5 e 1,5 característicos desses sítios, tendo valores crescentes de $\alpha(440-870 \mathrm{~nm})$ com aumento de AOD $(440 \mathrm{~nm})$ indicando contribuição de partículas de moda fina na coluna atmosférica nesses ambientes, associados com mistura de aerossóis e aerossóis de queima de biomassa e/ou urbano.

A análise do espectro de AOD (440 nm) versus $\alpha(440-870 \mathrm{~nm})$ para os sítios em Floresta permitiu identificar maior densidade de dados relacionado a mistura de aerossóis e aerossóis de queima de biomassa e/ou urbano no sítio de Rio Branco (AC), tendo médias mensais de $\alpha(440-870 \mathrm{~nm})$ crescentes para o sítio de Rio Branco $(A C)$, com maior sazonalidade observada para o sítio de Ji-Paraná (RO). 


\section{AGRADECIMENTOS}

À Capes pela proposta DINTER (UFMT/IEAA/UFAM) através do projeto 013/2012, ao Programa de Pós-Graduação em Física Ambiental da Universidade Federal do Mato Grosso e ao grupo de Estudos do Instituto de Física da USP (em especial ao professor Paulo Artaxo) pela utilização dos dados da rede AERONET.

\section{REFERÊNCIAS BIBLIOGRÁFICAS}

ANDREAE, M. O; ARTAXO, P; FISCHER, H; FREITAS, S. R. Transport of biomass burning smoke to the upper troposphere by deep convection in the equatorial region. Geophysical Research Letters, v. 28, n. 6, p. 951-954, 2001.

ARTAXO, P. The atmospheric component of biogeochemical cycles in the Amazon basin. The biogeochemistry of the Amazon Basin, p. 42-52, 2001.

BALARABE, M.; ABDULLAB, K.; NAWAWI, M. Long-Term Trend and Seasonal Variability of Horizontal Visibility in Nigerian Troposphere. Atmosphere, v. 6, p. 1462-1486, 2015. ISSN http://doi.org/10.3390/atmos6101462.

C.L.REDDINGTON, E. W. B. D. A. R. P. A. W. T. M. H. C. E. D. V. S. Air Quality and human health improvements from reductions in deforestation-related fire in Brazil. Nature Geoscience, v. 16 , setembro 2015. ISSN DOI: $10.1038 /$ NGEO02535.

CHINEKE, T. C.; CHIEMEKA, I. U. Harmattan Particulate Concentration and Health Impacts in Sub-Sahara Africa. The African Review of Physics, v. 3, p. 125-135, 2009.

FLORENCE, D.L; YVON, C. H; SABINE, H.; PIERRE, O. What Do We Know about Effects of Desert Dust on Air Quality and Human Health in West Africa Compared to other Regions?, 409, 2010. 1-8.

HABID, G; VENKATARAMAN, C; CHIAPELLO, I; RAMACHANDRAN, S; BOUCHER, O; REDDY, M.S. Seasonal and Interannual Variability in Absorbing Aerosols over India Derived from TOMS: Relationship to Regional Meteorology and Emissions. Atmospheric Environment, v. 40, p. 1909-1921, 2006. ISSN http://dx.doi.org/10.1016/i.atmosenv.2005.07.077.

HOLBEN, B.N; ECK, T.F; SLUTSKER, I; TANRE, D; BUIS, J.P; SETZER, A; VERMOTE, E; REAGAN, J.A; KAUFMAN, Y.J; NAKAJIMA, T; LAVENU, $F$; JANKOWIAK, I; SMIRNOV, A. AERONET-A Federated Instrument Network and Data Archive for Aerosol Characterizations. Remote Sensing of Environment, v. 66, p. 1-16, 1998. ISSN http://dx.doi.org/10.1016/S0034-4257(98)00031-5.

KASKAOUTIS, D.G; KAMBEZIDIS, H.D; NASTOS, P.T; KOSMOPOULOS, P.G. Study on an Intense Dust Storm over Greece. Atmospheric Environment, v. 42, p. 6884-6896, 2008. ISSN http://dx.doi.org/10.1016/j.atmosenv.2008.05.017.

KAUFMAN, Y.J; HOBBS, P.V; KIRCHHOFF, V.W.J; ARTAXO, P; REMER, L.A; HOLBEN, B.N; KING, M.D; WARD, D.E; PRINS, E.M; LONGO, K.M; MATTOS, L.M; NOBRE, C.A; SPINHIRNE, J.D; JI, Q; THOMPSON, A.M; GLEASON, J.F; CHRISTOPHER, S.A; TSAY, S.C. Smoke, Clouds, and Radiation - Brasil (SCAR-B) experiment. Journal of Geophysical Research, v. 103, n. D24, p. 31783-31808, 1998. 
KEHINDE, O.O; AYODEJI, O; VICENT, O.A. A Long-Term Record of Aerosol Index from TOMS Observations and Horizontal Visibility in Sub-Saharan West Africa. International Journal of Remote Sensing, v. 33, p. 6076-6093, 2015. ISSN http://dx.doi.org/10.1080/01431161.2012.676689.

MUKHTAR BALARABE, K. A. M. N. Properties and Identification of Different Aerosol Types Based on AERONET data over Sub-Sahara West-Africa. Atmospheric and Climate Sciences, v. 6, p. 13-28, 2016. ISSN http://dx.doi.org/10.4236/acs.2016.61002.

NWAFOR, O. K.; CHINEKE, T. C.; PINKER, R. T. Seasonal Characteristics of Aerosol Optical Properties at a Sub-Sahara Site. Atmospheric Research, v. 85, p. 38-51, 2007. ISSN http://dx.doi.org/10.1016/j.atmosres.2006.11.002.

OGUNJOKI, K; AJAYI, V; BALOGUN, I; OMOTOSHO, J; HE, Z. The Synoptic and Optical Characteristics of the Harmattan Dust Spells over Nigeria. Theoretical and Applied Climatology, v. 93, p. 91-105, 2008. ISSN http://dx.doi.org/10.1007/s00704-007-0332-2.

OYEM, A. A.; A. F, I. Analysis of Atmospheric Aerosol Loading over Nigeria. Environmental Research Journal, v. 4, p. 145-156, 2010. ISSN http://dx.doi.org/10.1063/1.4915232.

P.B, RUSSELL; R.W, BERGSTROM; Y, SHINOZUKA; A.D, CLARKE; P.F, DE CARLO; J.L, JIMENEZ; J.M, LIVINGSTON; J, REDEMANN; O, DUBOVIK; A, STRAWA. Absortion angstrom exponent in aeronet and related data as an indicator of aerosol composition. Atmos.Chem.Phys., v. 10, p. 1155-1169, 2010.

PROSPERO, J.M; GINOUX, P; TORRES, O; NICHOLSON, S.E; GILL, T.E. Environmental Characterization of Global Sources of Atmospheric Soil Dust Identified with the Nimbus7 Total Ozone Mapping Spectrometer (TOMS) Absorbing Aerosol Product. Reviews of Geophysics, v. 40, p. 1-31, 2002. ISSN http://dx.doi.org/10.1029/2000RG000095.

REMER, L.A; KAUFMAN, Y; HOLBEN, B.N; THOMPSON, A.M; MCNAMARA, D.P. Biomass burning aerossol size distribution and modeled optical properties. Journal of Geophysical Research, v. 103, p. 31879-31891, 1998.

SCHUSTER , G.; DUBOVIK O; HOLBEN, B. Angstrom exponent and bimodal aerosol size distributions. J. Geophys. Res., v. 111:DO7207, 2006. ISSN doi: 10.1029/2005JD006328.

TAN, F; WEI, Y. K; WAN, S. H; YEAP, E. C; LIM, H. S; ABDULLAH, K. Investigation of Aerosol Distribution Patterns and Its Optical Properties at Different Time Scale by Using LIDAR System and AERONET. AIP Conference Proceedings, v. 1657, 2015. ISSN Article ID: 130001. http://dx.doi.org/10.1063/1.4915232.

TOLEDANO, C; CACHORRO, V.E; BERJON, A; DE FRUTOS, A.M; SORRIBAS, M; DE LA MORENA, B.A; GOLOUB, P. Aerosol optical depth and Angstrom exponent climatology at El Arenosillo AERONET site (Huelva, Spain). Q. J. R. Meteorol. Soc, v. 133, p. 795-807, 2007. ISSN DOI:10.1002/qj.54.

VERGAZ, R; CACHORRO, VE; DE FRUTOS, AM; VILAPLANA, JM; DE LA MORENA, $B A$. Columnar characteristics of aerosols y espectroradiometer measuments in the maritime area of the Cadiz Gulf (Spain). Int. J. Climatol, v. 25, p. 1781$1804,2005$. 
Y. K, WEI; S. H, WAN; E. C, YEAP; H. S, LIM; K., ABDULLAH; TAN, F. Investigation of Aerosol Distribution Patterns and Its Optical Properties at Different Time Scale by Using LIDAR System and AERONET. AIP Conference Proceedings, p. 1657, 2015. ISSN http://dx.doi.org/10.1063/1.4915232. 